\title{
LACTATION AND LACTATIONAL AMENORRHOEA WITH POST-PARTUM IUCD INSERTIONS
}

\author{
VERA HINGORANI AND G. R. UMA BAI \\ Department of Obstetrics and Gynaecology, \\ All India Institute of Medical Sciences, New Delhi-16
}

(Received 7th Fuly 1970)

The post-partum period is considered as an ideal period for propagating any birth control technique as women are highly motivated and a number of them are under some medical care. For the introduction of an intra-uterine contraceptive device (IUCD) the post-partum period was also found satisfactory (Hingorani, 1966; Hingorani \& Uma Bai, 1968; Hingorani, Uma Bai \& Kakkar, 1969a; Phatak, 1969) as insertion was found to be easy and painless owing to the patulous os; there were no complaints of post-insertional bleeding on account of the natural presence of the lochia. It was also felt that when the lochia stopped the patient would then go into lactational amenorrhoea and a significant side effect of bleeding present in non-puerperal insertions would be minimized. However, as the effects of post-partum IUCD insertions on lactational amenorrhoea and lactation were not known, this study was undertaken.

One hundred and eighty-five post-partum women were fitted with a $30-\mathrm{mm}$ Lippes loop using a modified inserter (Hingorani, 1968) on the 3rd to 7th post-partum day and another 106 post-partum women (without an IUGD) were observed as control group. Haemoglobin estimation and bacteriological studies on the cervical swab were carried out initially and after 1, 3, 6, 9 and 12 months in both groups. In addition, details regarding the amount and duration of lochial discharge, lactation, establishment of period, menstrual pattern and any other symptoms in both groups were recorded and patients were followed up for 4 years. Observations on the results of cervical swab cultures (Uma Bai, Bhujwala, Prakash \& Hingorani, 1970), lochia and menstrual patterns (Hingorani, 1970) and other symptomatology (Hingorani, Uma Bai \& Kakkar, 1969b) have been reported elsewhere. This report records the observations on the duration of lactation and lactational amenorrhoea.

The duration of lactation in the study group varied between 0 and 36 months, the average being 10.86 months, with $82 \%$ of women lactating for more than 1 month. In the control group, the lactation period varied between 0 and 30 months, the average being 6.99 months with $84 \%$ of women lactating for more than 1 month. Detailed distribution of women in relation to duration of lactation is shown in Text-fig. 1. The difference in the duration of lactation in the two groups was not statistically significant $(P>0.05)$. 
In the study group, menstruation recommenced 1 to 16 months (average 4.78 months) after the delivery, whereas in the control group, menstruation was resumed after 1 to 14 months (average 5.26 months). The difference in the period of lactational amenorrhoea between the two groups was not statistically significant $(P>0.05)$. The distribution of women in relation to the period of

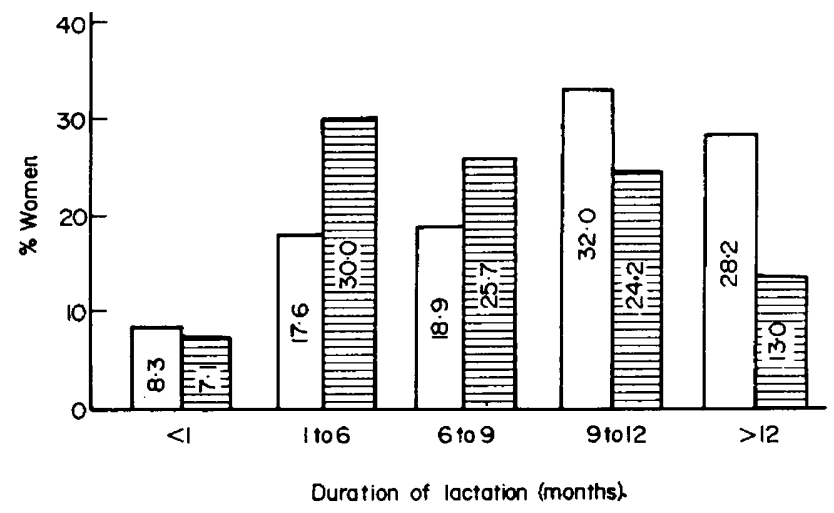

TeXT-FIG. 1. Duration of lactation in study (open columns) and control (hatched columns) groups.

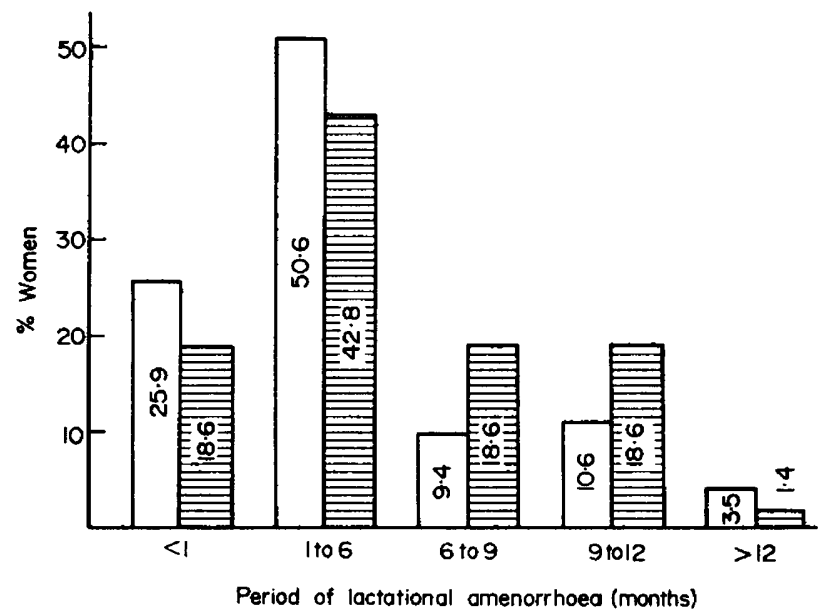

TexT-Fig. 2. Period of lactational amenorrhoea in study (open columns) and control (hatched columns) groups.

lactational amenorrhoea is shown in Text-fig. 2. The average duration of lactational amenorrhoea as reported by Malkani \& Mirchandani (1960) from the same city, was 5.25 months. This is comparable to the observations in the present study.

It is concluded that the post-partum IUGD insertions did not affect the duration of lactation or lactational amenorrhoea.

This study was conducted with assistance from the Indian Council of Medical Research. 


\section{REFERENCES}

Hingorani, V. (1966) Early puerperal and post abortal IUCD insertion. Proceedings of 2nd Seminar on Intrauterine Contraceptive Devices, New Delhi, p. 53. Ed. Somnath Roy. Central Family Planning Institute, New Delhi.

Hingorani, V. (1968) Modified inserter for post partum IUD. Obstet. Gynec., N.Y. 32, 854.

Hingorani, V. (1970) Menstrual pattern and lochia in women with post partum IUCD insertion. $A m$. 7. Obstet. Gynec. (In press).

Hingorani, V. \& Uma BaI, G. R. (1968) Early post partum IUCD insertions. F. Obstet. Gynec. India, 18, 249.

Hingorani, V., UMA BAI, G. R. \& KAKKAR, A. N. (1969a) Comparative study of symptomatology in women with early post partum IUCD insertions and in control group of women without devices. In: Review of Research in India on IUCD, p. 194. Ed. K. R. Laumas. Indian Council of Medical Research, New Delhi.

Hingorani, V., UMa BaI, G. R. \& KaKkar, A. N. (1969b) Clinicopathological study in women with post partum IUCD insertions. In: International Seminar on Maternal Mortality and Biology of Reproduction, p. 91.

Malkani, P. K. \& Mrrchandani, J. J. (1960) Menstruation during lactation. F. Obstet. Gynec. India, 11,11 .

Phatak, L. V. (1969) Comparative study of puerperal and nonpuerperal IUCD insertions. In: Review of Research Work in India on IUCD, p. 189. Ed. K. R. Laumas. Indian Council of Medical Research, New Delhi.

Uma Bai, G. R., Bhujwala, R. A., Prakash, O. \& Hingorani, V. (1970) A bacteriological study in women with early post partum intrauterine contraceptive device insertions. F. med. Res. 58, 258. 